\title{
Disparities in severe shigellosis among adults - Foodborne diseases active surveillance network, 2002-2014
}

\author{
Lindsey S. McCrickard*, Stacy M. Crim, Sunkyung Kim and Anna Bowen
}

\begin{abstract}
Background: Shigella causes approximately 500,000 illnesses, 6000 hospitalizations, and 40 deaths in the United States annually, but incidence and populations at risk for severe shigellosis among adults are unclear. This study describes severe shigellosis among US adults.

Methods: We analyzed Foodborne Diseases Active Surveillance Network data for infections caused by Shigella among adults $\geq 18$ years old during 2002-2014. Criteria to define severe shigellosis included hospitalization, bacteremia, or death. We estimated annual incidence of shigellosis per 100,000 among adult populations, and conducted multivariable mixed-effects logistic regression to assess associations between severe shigellosis, demographic factors and Shigella species among adults with shigellosis.

Results: Among 9968 shigellosis cases, 2764 (28\%) were severe. Restricting to cases due to S. sonnei and S. flexneri, median annual incidence of severe shigellosis among adults was 0.56 and highest overall incidence was among black males 18-49 years old (1.58). Among adults with shigellosis, odds of severe disease were higher among males than females aged 18-49 years old (OR $[95 \% \mathrm{Cl}]=1.32[1.15-1.52], p<0.001)$ and among males than females with $S$. flexneri infections $(\mathrm{OR}[95 \% \mathrm{Cl}]=1.39[1.10-1.75], p=0.005)$. The odds of severe shigellosis were higher among blacks than whites $(\mathrm{OR}[95 \% \mathrm{Cl}]=1.36[1.22-1.52], \mathrm{p}<0.001)$.

Conclusions: Among adults, men 18-49 years old, particularly blacks, have the highest incidence of severe shigellosis. Among adults with shigellosis, severe shigellosis was associated with being male in age group 1849 years, with infections caused by S. flexneri, and with black race. Future research should assess associations between severe shigellosis and sexual practices, antimicrobial resistance, comorbidities, and access to care.
\end{abstract}

Keywords: Shigellosis, Epidemiology, Adult, MSM

\section{Background}

Shigellosis is a diarrheal illness caused by Shigella sonnei, S. flexneri, S. dysenteriae, or S. boydii. Shigellosis causes an estimated 500,000 illnesses, 6000 hospitalizations, and 40 deaths annually in the United States [1,2]. Globally, an estimated 80-165 million cases of shigellosis occur annually, with the majority of cases occurring in developing countries [3]. The route of disease transmission is fecaloral and the infectious dose is extremely low; as few as 10 organisms can cause illness [1]. Most persons who are

\footnotetext{
*Correspondence: vjf4@cdc.gov; Imccrick@gmail.com Division of Foodborne, Waterborne and Environmental Diseases, Centers for Disease Control and Prevention, 1600 Clifton Road NE, Atlanta, GA 30333, USA
}

infected with Shigella develop diarrhea one or two days enced higher rates of shigellosis than men, likely due to close contact between affected children and their female caretakers [4]. For reasons that are unclear, among shigellosis infections reported to the Foodborne Diseases Active Surveillance Network [5] since 2009, incidence has been higher among males than females [6].

Shigellosis can cause severe illness and can lead to complications including septicemia, post-infectious arthritis, persistent episodes of gastroenteritis, hemolytic uremic tibiotics are frequently prescribed because they slightly shorten the course of the illness and decrease fecal shed- 
syndrome, or seizures $[1,7,8]$. The severity of illness varies by Shigella species. S. sonnei and S. flexneri, the two most common causes of shigellosis in the United States, typically cause mild diarrhea; however, both pathogens, particularly S. flexneri, can also cause bloody diarrhea and cramps [9]. In contrast, S. dysenteriae can cause large outbreaks of severe bloody diarrhea, but U.S. cases are rare and usually associated with international travel [3].

Few studies have assessed populations at risk for severe shigellosis. Although young children were at highest risk of Shigella related mortality in studies in Bangladesh [10] and the United States, some data now suggest an association between shigellosis severity and HIV-infection [11, 12]. Additional reports have shown disproportionate levels of shigellosis among men who have sex with men (MSM), particularly those with HIV infection [13, 14], and high levels of antimicrobial resistance in Shigella isolates from MSM $[15,16]$. However, it remains unclear whether disparities in shigellosis severity exist among adult populations. To help clarify, we reviewed laboratory-confirmed cases of Shigella infection reported to the Foodborne Diseases Active Surveillance Network (FoodNet) to define the incidence of severe shigellosis and to explore associations between demographic and clinical characteristics and disease severity among US adults.

\section{Methods}

We included all cases of shigellosis among adults aged 18 years or older reported to FoodNet from 2002 to 2014. FoodNet is a collaborative program among the Centers for Disease Control and Prevention (CDC), 10 state and local public health departments, the United States Department of Agriculture's Food Safety and Inspection Service (USDA-FSIS) and the Food and Drug Administration (FDA) [17]. FoodNet conducts active, population-based surveillance for laboratory-confirmed infections caused by 9 pathogens transmitted commonly through food, including Shigella species [17]. The FoodNet catchment area includes approximately $15 \%$ of the US population. FoodNet collects clinical and epidemiologic data, including source of isolate, state of residence, hospitalization, and death. Deaths and hospitalizations occurring within 7 days of specimen collection are attributed to the infection. We defined a case of severe shigellosis as Shigella infection including hospitalization, bacteremia (i.e., blood was recorded as source of isolate), or death.

We described demographic characteristics of Shigella infections by species and disease severity (severe and nonsevere), restricting analysis to those for whom age, race, and sex were known for further analysis. We categorized Asian/Pacific Islander and Native American races as "other race" due to small case numbers. Ethnicity was missing in $13.5 \%$ of included cases and ethnicity data incompleteness varied by race ( $10 \%$ for blacks, $14 \%$ for whites, $18 \%$ for other), year (8\% to $20 \%)$ and across FoodNet sites (1\% to $30 \%)($ all $p<0.05)$. Thus, we did not analyze ethnicity data because of concerns about selection bias. We restricted incidence and modeling analyses to shigellosis caused by either S. sonnei and S. flexneri infections due to the small number of $S$. dysenteriae and S. boydii infections. Shigellosis incidence was similar by age across persons 18-49 years old; thus, cases among persons of these ages were combined into one age group for this analysis. We calculated the median annual reported incidence of shigellosis and severe shigellosis per 100,000 persons in the surveillance area by sex, race (black, white, other), Shigella species (S. flexneri, S. sonnei), and age group (18-49, $\geq 50$ years) using annual U.S. Census Bureau population data for the surveillance area from 2015.

To further examine the associations between severity of shigellosis, demographics, and Shigella species among adults with shigellosis, we used a mixed-effects multivariable logistic regression model, treating disease severity as a binary outcome, and sex, age group, race, Shigella species and specimen collection year as independent variables. To account for the unknown factors that cause variation in site-specific disease severity rates across FoodNet sites, a random intercept was added in the model. From our exploratory analysis, the risk difference of severe shigellosis by sex was more apparent in 18-49 year olds than in $\geq 50$ year olds. A similar difference was also apparent by Shigella species. To assess these potential interactions, we included two interaction terms, one between sex and age group, and one between sex and Shigella species. $P$-values $<0.05$ were considered significant. All data analysis was performed using SAS 9.3.

\section{Results}

A total of 12,819 shigellosis cases among adults were reported to FoodNet from 2002 to 2014, of which 9968 (78\%) had complete age, race, species and sex variables and were used in this analysis. The distributions of race and age were similar among the included and excluded cases, but the included group contained a higher proportion of males than the excluded group (53\% vs. 49\%). Overall, 7063 (71\%) were caused by S. sonnei, 2748 (28\%) by S. flexneri, $111(1.1 \%)$ by S. boydii, and $46(0.5 \%)$ by S. dysenteriae; 7204 (72\%) were classified as non-severe and 2764 (28\%) were classified as severe (Table 1). Severe shigellosis was most prevalent among S. flexneri infections (34\%), followed by those caused by S. sonnei (25\%), S. boydii (21\%), and S. dysenteriae (20\%). Among illnesses classified as severe, 98 (3.5\%) fulfilled more than one severity criterion (i.e., hospitalized and bacteremic, or bacteremic and died). Of severe cases, 2735 (99\%) were hospitalized, 117 (4\%) were bacteremic, and $11(0.4 \%)$ died. Hospitalization length was known for 2653 (97\%) of hospitalized patients. Median hospitalization length was 3 days [Interquartile range: $2-4$ days]. None of 
Table 1 Demographic characteristics of shigellosis cases by species of infection and disease severity among adults $\geq 18$ years old-FoodNet, 2002-2014

\begin{tabular}{|c|c|c|c|c|c|c|c|c|c|c|c|c|c|c|c|c|c|c|c|c|}
\hline & \multicolumn{4}{|c|}{$\begin{array}{l}\text { All } \\
(N=9968)\end{array}$} & \multicolumn{4}{|c|}{$\begin{array}{l}\text { Shigella sonnei } \\
(N=7063)\end{array}$} & \multicolumn{4}{|c|}{$\begin{array}{l}\text { Shigella flexneri } \\
(N=2748)\end{array}$} & \multicolumn{4}{|c|}{$\begin{array}{l}\text { Shigella boydii } \\
(N=111)\end{array}$} & \multicolumn{4}{|c|}{$\begin{array}{l}\text { Shigella dysenteriae } \\
(N=46)\end{array}$} \\
\hline & \multicolumn{2}{|c|}{ Non-severe } & \multicolumn{2}{|c|}{ Severe } & \multicolumn{2}{|c|}{ Non-severe } & \multicolumn{2}{|c|}{ Severe } & \multicolumn{2}{|c|}{ Non-severe } & \multicolumn{2}{|c|}{ Severe } & \multicolumn{2}{|c|}{ Non-severe } & \multicolumn{2}{|c|}{ Severe } & \multicolumn{2}{|c|}{ Non-severe } & \multicolumn{2}{|c|}{ Severe } \\
\hline & $n$ & (\%) & $n$ & $\overline{(\%)}$ & $n$ & $(\%)$ & $n$ & $\overline{(\%)}$ & $n$ & (\%) & $n$ & $(\%)$ & $n$ & (\%) & $n$ & $(\%)$ & $n$ & $(\%)$ & $n$ & (\%) \\
\hline All & 7204 & (72) & 2764 & (28) & 5271 & (76) & 1792 & (25) & 1808 & (66) & 940 & (34) & 88 & (79) & 23 & (21) & 37 & (80) & 9 & (20) \\
\hline \multicolumn{21}{|l|}{ Sex } \\
\hline Male & 3706 & (70) & 1576 & (30) & 2219 & (75) & 750 & (25) & 1434 & (64) & 810 & (36) & 41 & (75) & 14 & (25) & 12 & (86) & 2 & (14) \\
\hline Female & 3498 & (75) & 1188 & (25) & 3052 & (75) & 1042 & (25) & 374 & (74) & 130 & (26) & 47 & (84) & 9 & (16) & 25 & (78) & 7 & (22) \\
\hline \multicolumn{21}{|l|}{ Age (years) } \\
\hline $18-49$ & 5680 & (74) & 1978 & (26) & 4140 & (77) & 1237 & (23) & 1456 & (67) & 727 & (33) & 59 & (86) & 10 & (14) & 25 & (86) & 4 & (14) \\
\hline$\geq 50$ & 1524 & (66) & 786 & (34) & 1131 & (67) & 555 & (33) & 352 & (62) & 213 & (38) & 29 & (69) & 13 & (31) & 12 & (71) & 5 & (29) \\
\hline \multicolumn{21}{|l|}{ Race } \\
\hline Black & 1852 & (65) & 1004 & (35) & 1212 & (69) & 535 & (31) & 614 & (57) & 460 & (43) & 18 & (75) & 6 & (25) & 8 & (73) & 3 & (27) \\
\hline White & 4893 & (75) & 1610 & (25) & 3756 & (76) & 1172 & (24) & 1051 & (71) & 421 & (29) & 61 & (82) & 13 & (18) & 25 & (86) & 4 & (14) \\
\hline Other & 459 & (75) & 150 & (25) & 303 & (78) & 85 & (22) & 143 & (71) & 59 & (29) & 9 & (69) & 4 & (31) & 4 & (67) & 2 & (33) \\
\hline
\end{tabular}

the illnesses caused by $S$. dysenteriae or $S$. boydii resulted in death or bacteremia. Males with shigellosis had a higher proportion of severe illnesses compared with women $(30 \%$ vs. 25\%). More cases of shigellosis were reported among adults 18-49 years old (7658) than among adults $\geq 50$ years old (2310). However, among all reported cases, the proportion of adults $\geq 50$ years old with severe shigellosis (34\%) was higher than the proportion of adults 18-49 years old with severe shigellosis (26\%). By race, the proportion of severe infections was highest among blacks (35\%) compared with whites $(25 \%)$ or other $(25 \%)$ race groups (Table 1$)$. Among the 10 sites reporting to FoodNet, Tennessee had the highest proportion (33.6\%) and Oregon had the lowest proportion $(18.7 \%)$ of illnesses that were severe. The median annual incidence of reported shigellosis caused by either S. sonnei or S. flexneri in FoodNet during 2002-2014 was 2.17 (Interquartile range, or IQR: 1.83-2.33) and was higher for $S$. sonnei than for $S$. flexneri (1.57 vs 0.60 , respectively) (Table 2). Severe shigellosis increased in incidence from 2011 to 2014 (Fig. 1). The median annual incidence of severe shigellosis was 0.39 (IQR: 0.31-0.43) for S. sonnei, 0.19 (IQR: 0.16-0.23) for S. flexneri and 0.56 (IQR: $0.49-0.70$ ) for the two species combined (Table 2). The median annual incidence of shigellosis was 2.22 in males and 1.89 in females, while the median annual incidence of severe shigellosis was 0.63 in males and 0.50 in females. The incidence of both shigellosis and severe shigellosis was higher among persons 18-49 years than adults $\geq 50$ years old, and among blacks than whites.

When calculating the incidence of shigellosis by race (black vs white), sex, and age group combined (8 groups in total); black males 18-49 years old had the highest median annual incidence of severe shigellosis (2.76), whereas white females $\geq 50$ years old had the lowest
(0.32) (Fig. 2a and b). Among infections caused by $S$. flexneri, black males 18-49 years old had the highest median annual incidence of severe shigellosis (1.58). Among infections caused by $S$. sonnei, black females $18-$ 49 years old had the highest median annual incidence of severe shigellosis (1.08) (data not shown).

In multivariable logistic regression, we observed significant interactions between sex and age group and between sex and species (all $p<0.01$ ) among adults with shigellosis. Thus, the associations between severity of

Table 2 Median annual incidence of infections caused by S. sonnei or S. flexneri by illness severity among adults aged $\geqq 18$ years - Foodborne Diseases Active Surveillance Network, 2002-2014

\begin{tabular}{|c|c|c|}
\hline & \multicolumn{2}{|c|}{ Incidence per 100,000 (IQR $\left.{ }^{\mathrm{a}}\right)$} \\
\hline & Severe shigellosis & Shigellosis \\
\hline All & $0.56(0.49-0.70)$ & $2.17(1.83-2.33)$ \\
\hline \multicolumn{3}{|l|}{ Sex } \\
\hline Male & $0.63(0.53-0.89)$ & $2.22(1.98-2.75)$ \\
\hline Female & $0.50(0.41-0.59)$ & $1.89(1.78-2.28)$ \\
\hline \multicolumn{3}{|c|}{ Age group, years } \\
\hline $18-49$ & $0.67(0.60-0.88)$ & $2.77(2.27-3.06)$ \\
\hline$\geq 50$ & $0.39(0.33-0.45)$ & $1.22(0.96-1.34)$ \\
\hline \multicolumn{3}{|l|}{ Race } \\
\hline Black & $1.42(1.13-1.91)$ & $3.58(3.45-4.95)$ \\
\hline White & $0.44(0.37-0.51)$ & $1.80(1.66-2.09)$ \\
\hline Other & Not assessed & Not assessed ${ }^{b}$ \\
\hline \multicolumn{3}{|l|}{ Species } \\
\hline S. flexneri & $0.19(0.16-0.23)$ & $0.60(0.56-0.64)$ \\
\hline S. sonnei & $0.39(0.31-0.43)$ & $1.57(1.24-1.73)$ \\
\hline
\end{tabular}

Interquartile range; ${ }^{b}$ Unable to assess because of limited sample size 


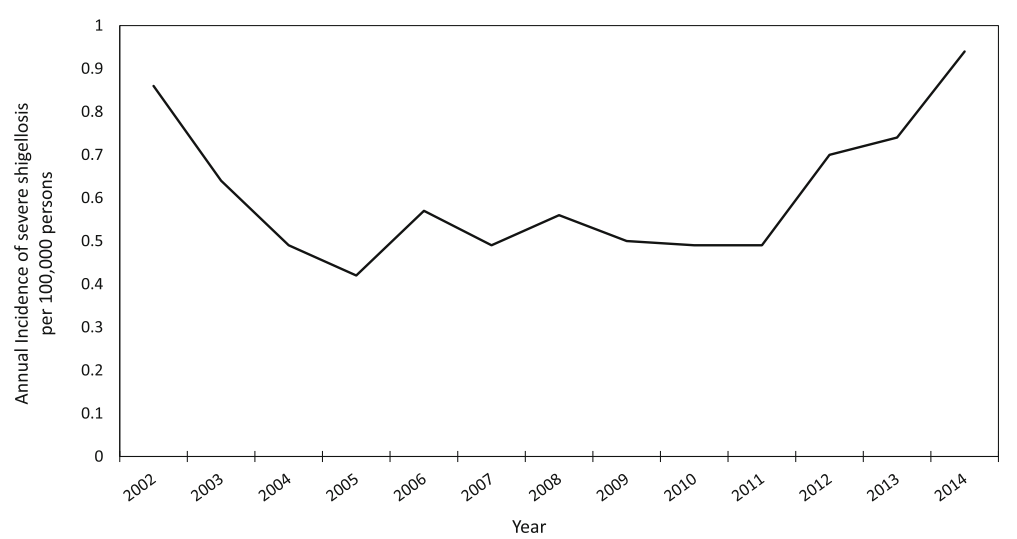

Fig. 1 Annual incidence of severe shigellosis per 100,000 persons among adults aged $\geq 18$ years — Foodborne Diseases Active Surveillance Network, 2002-2014
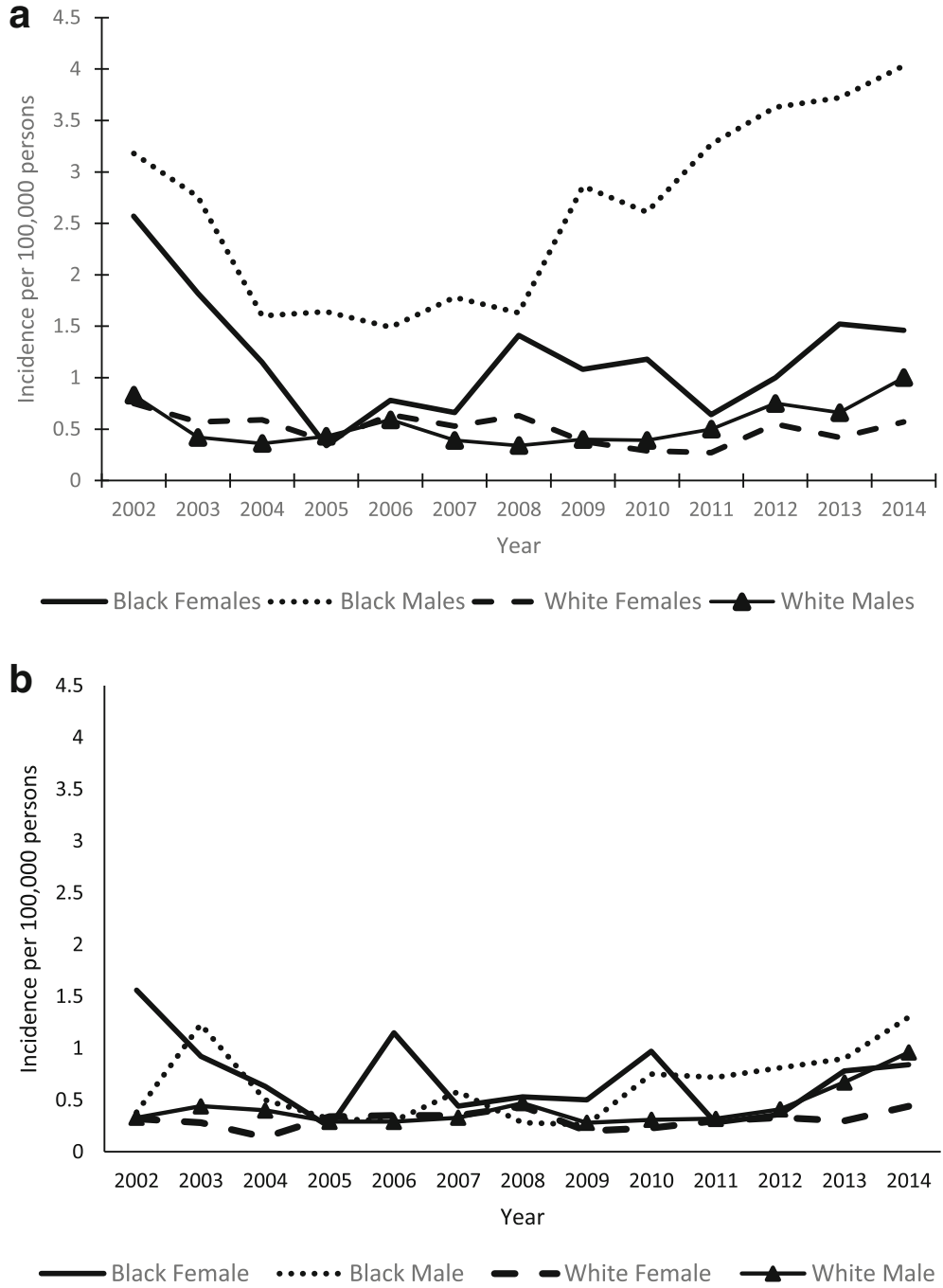

Fig. 2 Annual incidence of severe shigellosis per 100,000 persons by race and sex in adults (a) 18-49 years of age and (b) $\geq 50$ years of age Foodborne Diseases Active Surveillance Network, 2002-2014 
infections and sex were presented by age group and Shigella species (Table 3). Among 18-49 year olds, the odds of severe shigellosis were higher for males than for females (OR: 1.32, 95\% confidence interval (CI): 1.15$1.52, p<0.01)$. However, among adults $\geq 50$ years old, no significant difference by sex was observed (OR: 1.07, 95\% CI: $0.88-1.30, p=0.51$ ). The odds of severe disease were higher for males than females among infections caused by S. flexneri, (OR: 1.39, p < 0.01) but not among infections caused by $S$. sonnei (OR: 1.02, 95\% CI: $0.90-$ $1.15, p=0.78$ ). Blacks had higher odds of severe disease compared with whites (OR: 1.36, 95\% CI: $1.22-1.52, p<$ 0.01 ) and other race groups (OR: $1.27,95 \%$ CI: $1.02-$ $1.58, p=0.04)$. The odds of severe shigellosis gradually increased by year during 2002-2014 (OR: 1.04, 95\% CI: $1.03-1.05, p<0.01)$. Site-level random effects were significant $(p<0.001)$, implying significant contextual influences on disease severity (data not shown).

\section{Discussion}

This study outlines the burden of severe illness from shigellosis among US adults, and shows significant differences in the risk of developing severe shigellosis by sex, age, race, and species of infection. Among adults in FoodNet, $S$. sonnei caused the greatest number of severe infections, and black men 18-49 years old had the highest incidence of severe shigellosis compared to other race, age, and sex groups. Disparities by sex and race existed: odds of severe illness were higher among men $18-49$ years than among women of the same age, among men compared with women infected with S. flexneri, and among blacks compared with whites or other races. Although a higher proportion of cases were severe among adults $\geq 50$ years old than among those 18-49 years old, incidence of severe shigellosis was far lower, and no disparities were found by sex, in the older age group. Our data additionally suggest that the incidence of severe shigellosis in adults has been increasing since 2005, whereas shigellosis incidence overall has shown a general decrease from 2009 to 2013 [18].

Race and ethnicity often correlate with social determinants of health, such as poverty, unemployment, and low educational attainment [19]. Racial and ethnic minorities may receive a different level of care compared with nonminority patients; non-Hispanic blacks consistently have the highest rate of potentially preventable hospitalization compared with other racial/ethnic groups in the United States, and have poor access to healthcare [20, 21]. Disparities exist by race and ethnicity for a wide range of infectious diseases, including shigellosis, syphilis, and HIV [22, 23]. Such disparities in sexually transmitted diseases (STDs) in the United States are especially stark, with incidence of chlamydia infection estimated to be 8 times higher in black men than white men in 2013 [24]. In our study, we also found an increased incidence of shigellosis and severe shigellosis among blacks.

In this analysis, men experienced higher incidence of both shigellosis and severe shigellosis than did women. The reason for the male predominance is unknown and we were unable to assess the impact of comorbidities and sexual practices in our findings. It is possible that the increased incidence could be driven by increases in Shigella infections in MSM. Between 1975 and 1985, the median age of U.S. males infected with $S$. flexneri increased from 5 to 26 years of age, likely driven by transmission among MSM [25]. In the UK, the incidence of shigellosis among HIV-infected men increased nearly 7-fold during 2004-2015, while incidence among women remained approximately an order of magnitude lower than that of HIV-infected men [13]. Several outbreaks of shigellosis have been documented among MSM internationally, including in the United States and the UK $[11,26]$, and MSM are at higher risk for shigellosis and STDs compared with women and exclusively heterosexual men $[11,27]$. Shigellosis can spread through sexual practices that increase exposure to feces, such as fisting or

Table 3 Factors associated with severe illness among adults aged $\geqq 18$ years with shigellosis — Foodborne Diseases Active Surveillance Network, 2002-2014

\begin{tabular}{|c|c|c|c|}
\hline & & Odds Ratio ${ }^{a}(95 \% \mathrm{Cl})$ & $P$-value \\
\hline \multicolumn{4}{|l|}{ Age group, years } \\
\hline $18-49$ & Male vs Female & $1.32(1.15-1.52)$ & $<0.001$ \\
\hline$\geq 50$ & Male vs Female & $1.07(0.88-1.30)$ & 0.51 \\
\hline \multicolumn{4}{|l|}{ Species } \\
\hline S. flexneri & Male vs Female & $1.39(1.10-1.75)$ & 0.005 \\
\hline S. sonnei & Male vs Female & $1.02(0.90-1.15)$ & 0.78 \\
\hline \multicolumn{4}{|l|}{ Race } \\
\hline Black vs White & & $1.36(1.22-1.52)$ & $<0.001$ \\
\hline Black vs Other & & $1.27(1.02-1.58)$ & 0.04 \\
\hline Specimen collection year & & $1.04(1.03-1.05)$ & $<0.001$ \\
\hline
\end{tabular}

${ }^{a}$ Results from a multivariable mixed-effects logistic regression model that included sex, age, species, race, data year and two interaction terms between sex $\&$ age and species \& sex as covariates 
direct oral-anal contact [11, 28, 29]. The prevalence of behaviors such as unprotected sex, oral-anal contact, and sex with multiple partners, which increase the risk for contracting shigellosis and other STDs, may be increasing among MSM [30, 31]. In addition, sero-sorting, or seeking out sexual partners of the same HIV status, can lead to increases in unprotected sex and further spread of STDs, including shigellosis [32, 33]. Shigellosis has been significantly associated with HIV infection in some outbreaks, and among 3481 domestically-acquired shigellosis cases among men in the UK occurring between 2004 and 2015, 21\% were associated with HIV infection [12, 13].

HIV infection is a risk factor for shigellosis [12], and shigellosis severity may be related to immunosuppression or decreased mucosal immunity with HIV infection [34]. Although data are limited, persons co-infected with HIV and Shigella generally have longer duration of bacterial shedding in feces, and may suffer from more severe illness [12, 28]. In South Africa, persons infected with HIV were 4.1 times more likely to die from shigellosis compared with non-infected persons [35]. HIV infection may also be associated with antimicrobialresistant shigellosis, complicating treatment and increasing the risk for more severe illness [36].

Although we could not assess the direct association between antimicrobial resistance and shigellosis severity, antimicrobial-resistant Shigella is classified as a "serious risk" pathogen by CDC [37], and data suggest resistance to the preferred therapeutic antimicrobials for shigellosis, including azithromycin, ciprofloxacin, and ceftriaxone, appears to be increasing in the United States [38-40]. An analysis of shigellosis outbreaks reported to CDC found that Shigella strains associated with outbreaks in MSM were significantly more likely to be resistant to the key therapeutic antimicrobials than were other Shigella strains [15]. Antimicrobial resistance has been associated with increased severity of other diseases, including salmonellosis [41], and can result in longer hospital stays [42]. With increasing prevalence of antimicrobial resistance, shigellosis may last longer and have more severe outcomes.

Our findings suggest severe shigellosis is increasing, especially among men 18-49 years of age, and could be driven by increases among MSM. Shigellosis questionnaires used during public health investigations should incorporate information regarding sexual practices or orientation and concurrent STDs to better define risk groups and guide interventions for severe shigellosis. Because the increase in severe shigellosis may also be associated with increases in antimicrobial resistance, epidemiologic studies should include antimicrobial resistance, treatment and clinical outcome data to further characterize these associations.

Lack of information about sexual orientation or practices, comorbidities such as HIV, and antimicrobial resistance limited our study. Small numbers of deaths and bacteremia cases prevented meaningful sub-analyses for these outcomes, and detailed information about clinical characteristics such as dysentery were not available. Limiting the dataset to cases with complete demographic variables underestimated incidence and may have introduced selection bias. However, since FoodNet is an active surveillance system, we assume no association between the absence of demographic data and disease severity. The racial disparities we found should be interpreted carefully, as non-severe cases of shigellosis may be underreported in groups with poor access to healthcare, including blacks [21], however incidence of shigellosis and severe shigellosis was highest among blacks, suggesting real disparities in burden and risk. Missing data limited our ability to analyze ethnicity, which has documented associations with shigellosis incidence [43]. Combining Asian, Pacific Islander and Native American races into a single category prevents identification of any disparities among these populations, limiting our ability to address the needs of these minority groups. Finally, findings from this study were based on data from only the 10 FoodNet sites. Data may not be generalizable to the US population due to unknown differences in characteristics between the surveillance population and the US population.

\section{Conclusions}

In conclusion, blacks, particularly men $18-49$ years old, experienced higher incidence of severe shigellosis compared to other subgrounds and during Shigella infections, they had higher odds of developing severe illness during Shigella infections, compared to others. The reasons for this are unclear, but may be associated with disparities in social determinants of health, sexual orientation or behaviors, antimicrobial resistance, comorbidities, or circulation of more pathogenic strains within certain populations. Based on these and previous findings, Shigella isolates from all persons requiring antimicrobial treatment should be tested for antimicrobial susceptibility. Effective public health interventions for targeted prevention of shigellosis among blacks and men 18-49 years old could dramatically reduce the burden of severe shigellosis. Counseling MSM about prevention of sexual transmission of shigellosis, including guidance about hygiene, use of barriers during sex, and avoiding sex while having diarrhea, is critical. Further studies are warranted to characterize potential associations between severe shigellosis and MSM, antimicrobial resistance, and comorbidities. Among shigellosis patients, clinicians should consider the increased possibility for severe illness among persons infected with S. flexneri, males aged 18-49 years old or anyone aged $\geq 50$ years old, and blacks. 


\section{Abbreviations}

CDC: Centers for Disease Control and Prevention; FDA: Food and Drug Administration; FSIS: Food Safety Inspection Service; HIV: Human immunodeficiency virus; IQR: Interquartile Range; MSM: Men who have sex with men; STD: Sexually transmitted diseases; USDA: United States Department of Agriculture

\section{Acknowledgements}

We would like to thank the following persons and groups for their contribution to this manuscript: Li Deng and the FoodNet staff.

\section{Funding}

None.

\section{Availability of data and materials}

The datasets used and/or analyzed during the current study are available in the FoodNet repository, https://www.cdc.gov/foodnet/index.html.

\section{Authors' contributions}

LM analyzed and interpreted FoodNet data. SC prepared SAS protocol for analyzing incidence and was a major contributor in writing the paper. SK prepared analytic model and was a major contributor in writing the paper. $A B$ assisted in interpretation of data and was a major contributor in writing the paper. All authors read and approved the final manuscript.

\section{Ethics approval and consent to participate}

The data used for this analysis was de-identified under a protocol reviewed and approved by CDC's IRB.

\section{Consent for publication}

Not applicable.

\section{Competing interests}

The authors declare that they have no competing interests.

\section{Publisher's Note}

Springer Nature remains neutral with regard to jurisdictional claims in published maps and institutional affiliations.

Received: 3 July 2017 Accepted: 23 January 2018

Published online: 07 February 2018

\section{References}

1. Centers for Disease Control and Prevention. Shigella - Shigellosis [https://www.cdc.gov/shigella/index.html]. Accessed 3 Nov 2016.

2. Scallan E, Hoekstra RM, Angulo FJ, Tauxe RV, Widdowson MA, Roy SL, Jones $J$, Griffin PM. Foodborne illness acquired in the United States-major pathogens. Emerg Infect Dis. 2011;17(1):7-15.

3. Centers for Disease Control and Prevention. Yellow Book [http://wwwnc. cdc.gov/travel/yellowbook/2016/infectious-diseases-related-to-travel/ shigellosis] Accessed 9 Nov 2016.

4. Cordell RL. The risk of infectious diseases among child care providers. J Am Med Womens Assoc. 2001;56(3):109-12.

5. Barton Behravesh C, Jones TF, Vugia DJ, Long C, Marcus R, Smith K, Thomas S, Zansky S, Fullerton $\mathrm{KE}$, Henao OL, et al. Deaths associated with bacterial pathogens transmitted commonly through food: foodborne diseases active surveillance network (FoodNet), 1996-2005. J Infect Dis. 2011;204(2):263-7.

6. Centers for Disease Control and Prevention. FoodNet Fast [https://wwwn. cdc.gov/foodnetfast/] Accessed 23 Mar 2017.

7. American Academy of Pediatrics. Shigella infections. In: Pickering L, Baker C, Kimberlin D, Long S, editors. Red book. 30th ed. Elk Grove Village: American Academy of Pediatrics; 2015. p. 707-9.

8. von Seidlein L, Kim DR, Ali M, Lee H, Wang X, Thiem VD, Canh DG, Chaicumpa W, Agtini MD, Hossain A, et al. A multicentre study of Shigella diarrhoea in six Asian countries: disease burden, clinical manifestations, and microbiology. PLoS Med. 2006;3(9):e353.

9. Keusch GT, Bennish ML. Shigellosis: recent progress, persisting problems and research issues. Pediatr Infect Dis J. 1989:8(10):713-9.

10. Struelens MJ, Patte D, Kabir I, Salam A, Nath SK, Butler T. Shigella septicemia: prevalence, presentation, risk factors, and outcome. J Infect Dis. 1985;152(4): 784-90.
11. Aragon TJ, Vugia DJ, Shallow S, Samuel MC, Reingold A, Angulo FJ, Bradford WZ. Case-control study of shigellosis in San Francisco: the role of sexual transmission and HIV infection. Clin Infect Dis. 2007;44(3):327-34.

12. Baer JT, Vugia DJ, Reingold AL, Aragon T, Angulo FJ, Bradford WZ. HIV infection as a risk factor for shigellosis. Emerg Infect Dis. 1999;5(6):820-3.

13. Mohan K, Hibbert M, Rooney G, et al. What is the overlap between HIV and shigellosis epidemics in England: further evidence of MSM transmission? Sex Transm Infect Published Online First. 2017; https:// doi.org/10.1136/sextrans-2016-052962. Accessed 11 June 2017.

14. Public Health England. Update on the epidemiology of Shigella in adults in London. 2017.

15. Bowen A, Grass J, Bicknese A, Campbell D, Hurd J, Kirkcaldy RD. Elevated risk for antimicrobial drug-resistant Shigella infection among men who have sex with men, United States, 2011-2015. Emerg Infect Dis. 2016;22(9):1613-6.

16. Murray $\mathrm{K}$, Reddy $\mathrm{V}$, Kornblum J, et al. Increasing antibiotic resistance in Shigella spp. from infected new York City residents, New York, USA. Emerg Infect Dis. 2017;23(2):332-5. https://doi.org/10.3201/eid2302.161203.

17. Centers for Disease Control and Prevention. Foodborne Diseases Active Surveillance Network (FoodNet) [https://www.cdc.gov/foodnet/about.html] Accessed 6 Feb 2017.

18. Centers for Disease Control and Prevention. National enteric disease surveillance: Shigella annual report, 2013. Atlanta, GA: US Department of Health and Human Services; 2016.

19. Meyer PA, Yoon PW, Kaufmann RB. CDC health disparities and inequalities report — United States, 2013. Morb Mortal Wkly Rep. 2013;62(3):3-5.

20. Moy E, Chang E, Barrett M. Potentially preventable hospitalizations United States, 2001-2009. MMWR Suppl. 2013;62(3):139-43.

21. Weinick RM, Zuvekas SH, Cohen JW. Racial and ethnic differences in access to and use of health care services, 1977 to 1996. Med Care Res Rev. 2000; 57(Suppl 1):36-54.

22. Racial disparities in nationally notifiable diseases-United States, 2002. MMWR Morb Mortal Wkly Rep. 2005:54(1):9-11.

23. Johnson AS, Beer L, Sionean C, Hu X, Furlow-Parmley C, Le B, Skarbinski J, Hall HI, Dean HD. HIV infection - United States, 2008 and 2010. MMWR Suppl. 2013;62(3):112-9.

24. Centers for Disease Control and Prevention. STDs in Racial and Ethnic Minorities [http://www.cdc.gov/std/stats13/minorities.htm] Accessed 22 Dec 2016.

25. Tauxe RV, McDonald RC, Hargrett-Bean N, Blake PA. The persistence of Shigella flexneri in the United States: increasing role of adult males. Am J Public Health. 1988:78(11):1432-5.

26. Simms I, Field N, Jenkins C, Childs T, Gilbart VL, Dallman TJ, Mook P, Crook PD, Hughes $G$. Intensified shigellosis epidemic associated with sexual transmission in men who have sex with men-Shigella flexneri and S. Sonnei in England, 2004 to end of February 2015. Euro Surveill. 2015;20:15.

27. Centers for Disease Control and Prevention. STDs in Men Who Have Sex With Men [http://www.cdc.gov/std/stats14/msm.htm] Accessed 1 Jan 2017.

28. Daskalakis DC, Blaser MJ. Another perfect storm: Shigella, men who have sex with men, and HIV. Clin Infect Dis. 2007;44(3):335-7.

29. Marcus U, Zucs P, Bremer V, Hamouda O, Prager R, Tschaepe H, Futh U, Kramer $M$. Shigellosis - a re-emerging sexually transmitted infection: outbreak in men having sex with men in Berlin. Int J STD AIDS. 2004;15(8):533-7.

30. Chen SY, Gibson S, Katz MH, Klausner JD, Dilley JW, Schwarcz SK, Kellogg TA, McFarland W. Continuing increases in sexual risk behavior and sexually transmitted diseases among men who have sex with men: San Francisco, Calif, 1999-2001, USA. Am J Public Health. 2002:92(9):1387-8.

31. Gilbart VL, Simms I, Jenkins C, Furegato M, Gobin M, Oliver I, Hart G, Gill ON, Hughes $\mathrm{G}$. Sex, drugs and smart phone applications: findings from semistructured interviews with men who have sex with men diagnosed with Shigella flexneri 3a in England and Wales. Sex Transm Infect. 2015;91(8):598-602.

32. Jin F, Prestage GP, Templeteon DJ, Poynten IM, Donovan B, Zablotska I, Kippax SC, Mindel A, Grulich AE. The impact of HIV seroadaptive behaviours on sexually transmissible infections in HIV-negative homosexual men in Sydney, Australia. Sex Transm Dis. 2012;39(3):191-4.

33. Grewal R, Allen VG, Gardner S, Moravan V, Tan DH, Raboud J, Bayoumi AM, Kaul R, Mazzulli T, McGee F, et al. Serosorting and recreational drug use are risk factors for diagnosis of genital infection with chlamydia and gonorrhoea among HIV-positive men who have sex with men: results from a clinical cohort in Ontario. Canada: Sex Transm Infect; 2016.

34. Nelson MR, Shanson DC, Hawkins DA, Gazzard BG. Salmonella, Campylobacter and Shigella in HIV-seropositive patients. AIDS. 1992; 6(12):1495-8 
35. Keddy KH, Sooka A, Crowther-Gibson P, Quan V, Meiring S, Cohen C, Nana T, Sriruttan C, Seetharam S, Hoosen A, et al. Systemic shigellosis in South Africa. Clin Infect Dis. 2012;54(10):1448-54.

36. Hoffmann C, Sahly H, Jessen A, Ingiliz P, Stellbrink HJ, Neifer S, Schewe K, Dupke S, Baumgarten A, Kuschel A, et al. High rates of quinolone-resistant strains of Shigella sonnei in HIV-infected MSM. Infection. 2013;41 (5):999-1003.

37. Centers for Disease Control and Prevention. Biggest Threats [http://www. cdc.gov/drugresistance/biggest_threats.html] Accessed 15 Apr 2017.

38. Centers for Disease Control and Prevention. National Antimicrobial Resistance Monitoring System (NARMS) 2014 human isolates surveillance report. Atlanta, GA: U.S. Department of Health and Human Services, CDC; 2016.

39. Centers for Disease Control and Prevention. CDC recommendations for diagnosing and managing Shigella strains with possible reduced susceptibility to ciprofloxacin. Atlanta: CDC; 2017.

40. Shiferaw B, Solghan S, Palmer A, Joyce K, Barzilay EJ, Krueger A, Cieslak P. Antimicrobial susceptibility patterns of Shigella isolates in Foodborne diseases active surveillance network (FoodNet) sites, 2000-2010. Clin Infect Dis. 2012;54(Suppl 5):S458-63.

41. Krueger AL, Greene SA, Barzilay EJ, Henao O, Vugia D, Hanna S, Meyer S, Smith K, Pecic G, Hoefer D, et al. Clinical outcomes of nalidixic acid, ceftriaxone, and multidrug-resistant nontyphoidal salmonella infections compared with pansusceptible infections in FoodNet sites, 2006-2008. Foodborne Pathog Dis. 2014;11(5):335-41.

42. Holmberg SD, Solomon SL, Blake PA. Health and economic impacts of antimicrobial resistance. Rev Infect Dis. 1987;9(6):1065-78.

43. Centers for Disease Control and Prevention. FoodNet surveillance report for 2014 (final report). Atlanta, Georgia: Department of Health and Human Services; 2014

\section{Submit your next manuscript to BioMed Central and we will help you at every step:}

- We accept pre-submission inquiries

- Our selector tool helps you to find the most relevant journal

- We provide round the clock customer support

- Convenient online submission

- Thorough peer review

- Inclusion in PubMed and all major indexing services

- Maximum visibility for your research

Submit your manuscript at www.biomedcentral.com/submit

) Biomed Central 